\title{
Smart integration of drive system for induction motor applications in electric vehicles
}

\author{
Mohamed K. Metwaly ${ }^{1}$, Mohammad Alsharef ${ }^{2}$, Nehmdoh A. Sabiha ${ }^{3}$, Ehab E. Elattar ${ }^{4}$, \\ Ibrahim B. M. Taha ${ }^{5}$, Amr M. Abd-Elhady ${ }^{6}$, Nagy I. Elkalashy ${ }^{7}$ \\ ${ }^{1,2,3,4,5,7}$ Electrical Engineering Department, College of Engineering, Taif University, Taif, Saudi Arabia \\ ${ }^{6}$ Electrical Engineering Department, Faculty of Engineering, Menoufia University, Shebin Elkom, Egypt
}

\section{Article Info}

Article history:

Received Sep 22, 2020

Revised Jan 15, 2021

Accepted Feb 5, 2021

\section{Keywords:}

Electric vehicle

Encoderless control

Induction motor

Torque control drive

\begin{abstract}
In this paper, a smart drive system of the induction motor (IM) is proposed and adapted for applications in electric vehicles (EVs). Objectively, the EV drive systems are robust over wide speed and torque ranges. The proposed drive system is independent of encoder (encoderless) and concerned with the torque control drive (TCD) and indirect rotor field-oriented control (IRFOC) using the sliding mode observer (SMO). This arrangement of monitoring system and control techniques are smartly integrated for the IM applications in EVs. The encoderless technique utilizes SMO to estimate the stator current, rotor flux angle, and rotor speed. The SMO is verified in motoring mode at very low and zero speed conditions. The accelerator pedal is utilized for TCD to generate the reference torque required to accelerate the EV by the driver. The rotor flux angle is estimated based on IRFOC method. The laboratory waveforms illustrate the robustness of the encoderless control of the IM-based torque control drive system in electrical vehicle applications at very low speed using SMO. The laboratory waveforms prove the validity of SMO with encoderless control of a smart dive system of the IM in EV applications under load torque/speed variations.
\end{abstract}

This is an open access article under the CC BY-SA license.

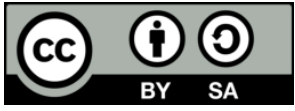

\section{Corresponding Author:}

Mohamed K. Metwaly

Electrical Engineering Department, College of Engineering

Taif University, 21974 Taif, Saudi Arabia

Email: m.metwally@tu.edu.sa

\section{INTRODUCTION}

Due to the increasing demand for smart cities and sustainable electrifications using renewable power generations, the recent research trends are proposed to increase the penetration of electric vehicles (EVs). However, the drive system of EV needs sensors for the rotor speed measurements. These sensors are not adapted with harsh environments changes such as mechanical vibrations, temperature changes, and dust. To solve these problems, the developments of encoderless of Induction Motor (IM) drives have been increased, recently. Encoderless speed estimation techniques are utilized in hostile environments and also for abnormal conditions in safety-critical applications in case of damage of speed sensor [1], [2].

The IMs have been good solutions in the field of EV drive systems, because they have many merits such as robustness, rigidity, simple construction, less cost, and less maintenance. Furthermore, the IM drives have been utilized in many position tracking applications, which need precise control action for example actuation, robotics, automation process, and guided process. These merits make the IMs a very good solution for industrial applications. Thus, precise position and speed controls are mandatory in EV drive systems during load torque/speed disturbances [1]. 
Sliding mode observer (SMO) is one of the models concerning encoderless speed estimation techniques for the motor drive systems. It can robustly and efficiently estimate the motor speed, rotor flux, rotor position, and motor torque, where only one observer gain is needed [3]. Also, a good, stable, and robustness performance against the parameters' sensitivity can be obtained over wide speed range of operation, as well as ease of implementation [4]-[5]. To keep the dynamic states of operations for the estimated variables, time-varying gains for the switching functions of the observer are used [6]. However, chattering is the main disadvantage of the SMO variable structure system. This system chattering is reduced using a sigmoid function and the observer is constructed based on a back electro-motive force (EMF) model for improving the effect of estimation [7]-[9].

In [10], a nonlinear SMO scheme is proposed for interior permanent magnet synchronous motor (IPMSM) considering maximum torque per ampere (MTPA), the SMO is utilized as speed estimator technique. Lyapunov stability analysis is achieved for both the controller and observer. A second-order SMO is used to estimate the rotor speed based on a super twisting algorithm and model reference adaptive system calculating principles [11]. A comparative study between full order SMO and improved integration for the voltage model (VM) is presented in [12]. In that study, the dc offset is estimated and kept by proportional plus integral (PI) compensator, in which all unwanted offsets and drifts are compensated in the acquisition terminals. However, due to the incorrect observer variables, a phase shift is observed in quasi-SMO (QSMO) or discrete-time SMO during the load changes [13]. Toward solving this problem, an adaptive QSMO is presented to calculate the extended EMF components for the IPMSM, in which are utilized to determine the rotor angle for the IPMSM. For robust encoderless control, an Iterative SMO (ISMO) is proposed in [14]. The ISMO enhances the estimated speed performance by minimizing the back EMF error.

In [15], a quadrature phase-locked loop (QPLL)-based on high order SMO for IPMSM with MTPA is presented to enhance the encoderless position control of IPMSM. The QPLL calculation method has immunity against noise and distortion effects. Improving the estimated rotor flux angle at very low speed operation based on SMO is presented in [16]. The proposed technique does not need any speed adaptation algorithm and has immunity to the deviation of speed estimation. A predictive SMO of the stator flux at a wide range of operating speed, the saliency of the machine due to it is saturation effect is utilized in [17]. A changeover algorithm is programmed to combine all modes of operations. Sliding mode reaching law (SMRL) is proposed in [18] to adapt the encoderless speed control operation of the IPMSM under different disturbances and uncertainties. The SMRL has a feature of adaptation according to the control system variations, as results in a reduction of the chattering problem, are done on the control input, while the tracking operation of the controller is maintained unchanged.

Nonsingular terminal sliding mode (NTSM) is integrated with high order sliding mode (HOSM) for estimating the IPMSM speed and its position [19]. To eliminate the chattering and to ensure observer stability, the HOSM control law is designed. In [20], a scheme of the encoderless speed estimation at a very low operating speed for the IMPSM utilizing SMO is investigated. The delay time due to the low pass filter or the chattering problem is solved using a sigmoid function for the sign or saturation function. Two SMOs with compound manifolds for the IM speed/flux observation is presented in [21]. The encoderless control of the IM-based model reference adaptive system (MRAS) for EV application is presented in [22].

In [23]-[25], an adaptive and robust position control for the IM is proposed. The switching gains are selected considering the system uncertainties. Also, the slip speed is used to estimate the rotor flux angle. As early mentioned, the main disadvantage of SMO is the chattering performance because the oscillations occur with high frequencies when sliding mode takes place. The solution of SMO problems is to eliminate the chattering and enhance the speed estimation accuracy, especially in low-speed region. However, the EV can be driven from zero speed up to its limit speed. To find a speed control universally over a very wide range of speed and independent of speed encoder is a challenge for the EV applications.

In this paper, main contributions are summarized by:

- Integrating a smart drive system of IM.

- Utilizing the SMO of speed estimation for the encoderless speed-controlled IM with torque control drives systems in EV applications.

- Implementing the indirect rotor field-oriented control (IRFOC) for the encoderless speed control of the IM drive systems in EVs in the laboratory using a digital signal processing DSpace-DS1103 control board.

- $\quad$ Evaluate the laboratory waveforms under extreme disturbances of the load torque/speed.

- Evaluate the effectiveness of the proposed smart encoderless IM drive system at very low and zero mechanical frequency. 


\section{MODEL DESCRIPTION OF IM}

The model of IM in the stationary reference frame taking the stator current and rotor flux as state variable is represented by (1) [26]:

$$
\frac{d}{d t}\left[\begin{array}{l}
\vec{i}_{s}^{s} \\
\vec{\lambda}_{r}^{s}
\end{array}\right]=\left[\begin{array}{ll}
A_{11} & A_{12} \\
A_{21} & A_{22}
\end{array}\right]\left[\begin{array}{l}
\vec{i}_{s}^{s} \\
\vec{\lambda}_{r}^{s}
\end{array}\right]+B \vec{u}_{s}^{s}
$$

where, $\overrightarrow{\vec{i}}_{s}^{s}$ is the stator current, $\vec{\lambda}_{r}^{s}$ is the rotor flux, $\vec{u}_{s}^{s}$ is the stator voltage, $A_{11}=a I, A_{12}=c I-c T_{r} \omega_{r} J$, $A_{21}=d I, \quad A_{22}=-\frac{1}{T_{r}} I+\omega_{r} J, B=\left[\begin{array}{ll}b & 0\end{array}\right]^{T} ; \quad a=-\left(\frac{R_{S}}{\sigma L_{S}}+\frac{L_{m}^{2}}{\sigma L_{s} L_{r} T_{r}}\right), \quad b=\frac{1}{\sigma L_{s}}, \quad c=\frac{1}{v T_{r}}, \quad d=\frac{L_{m}}{T_{r}}, \quad \sigma=1-\frac{L_{m}^{2}}{L_{s} L_{r}}$, $T_{r}=\frac{L_{r}}{R_{r}}, \quad v=\frac{\sigma L_{s} L_{r}}{L_{m}} \quad I=\left[\begin{array}{ll}1 & 0 \\ 0 & 1\end{array}\right], J=\left[\begin{array}{cc}0 & -1 \\ 1 & 0\end{array}\right]$

$R_{s}$ and $R_{r}$ are the stator and rotor resistances, respectively. $L_{s}$ and $L_{r}$ are the stator and rotor inductances, respectively. $L_{m}$ is the magnetizing inductance, and $\omega_{r}$ is the rotor speed. $\sigma_{\text {is }}$ the leakage coefficient, and $T_{r}$ is the rotor time constant.

The equation of electromechanical torque is illustrated by (2) and (3):

$$
\begin{aligned}
& T_{e}=J \frac{d \omega_{r}}{d t}+B \omega_{r}+T_{L} \\
& T_{e}=\frac{3}{2} \frac{P}{2} \frac{L_{m}}{L_{r}}\left(I_{q s}^{s} \lambda_{d r}^{s}-I_{d s}^{s} \lambda_{q r}^{s}\right)
\end{aligned}
$$

where $P$ is the IM pole pairs, ${ }_{q s}^{s}, I_{d s}^{s},{ }_{q r}^{s}$, and $\lambda_{d r}^{s}$ are quadrature-axis, direct-axis stator currents and rotor fluxes in stationary reference frame respectively. The rotor angle is computed as (4):

$$
\theta_{r}=\int \omega_{r} d t
$$

\section{SMO FOR POSITION AND SPEED ESTIMATIONS}

The model presented in [26] is utilized to determine the rotor speed and position as described as (5).

$$
\hat{\omega}_{r}=\gamma \int\left[F\left(\hat{i}_{d s}^{s}-i_{d s}^{s}\right) \cdot \hat{\lambda}_{q r}^{s}-F\left(\hat{i}_{q s}^{s}-i_{q s}^{s}\right) \cdot \hat{\lambda}_{d r}^{s}\right] d t
$$

where $i_{d s}^{s}, \hat{i}_{d s}^{s}, i_{q s}^{s}, \hat{i}_{q s}^{s}$ are the actual and estimated stator currents in direct and quadrature axes, respectively. ${ }_{d r}^{s}$, $\hat{\lambda}_{q r}^{s}$ are the estimated rotor flux in direct and quadrature axes respectively. $\mathrm{F}$ is the tan-sigmoid switching function described by (6):

$$
\mathrm{F}(\mathrm{s})=\tan \operatorname{sig}(\mathrm{S})=\frac{2}{1+e^{-2 S}}-1
$$

the estimated rotor position is described by (7):

$$
\hat{\theta}_{r}=\int \hat{\omega}_{r} d t
$$

\section{EV-INCORPORATED ENCODERLESS SPEED ESTIMATION BASED ON SMO WITH TCD}

The schematic diagram of the encoderless speed estimation utilizing SMO for IRFOC of the IM based TCD in EV applications is shown in Figure 1. The torque demand signal is inserted into the IM drive 
system using accelerator pedal-based torque control drive technique in EV applications by the driver. This drive system for the EV is smart as it is independent of the encoders. As depicted in the figure, the reference $\mathrm{q}$-axis current component in synchronous reference frame is evaluated from the electromagnetic torque formula as (8) [22]:

$$
i_{q}^{*}=\frac{L_{r} T^{*}}{1.5 P L_{m}^{2} i_{d}^{*}}
$$

Also, the reference d-axis current component in synchronous reference frame is dependant of the reference rotor flux amplitude $\lambda_{r}^{*}$ and magnetizing inductance as (9):

$$
i_{d}^{*}=\frac{\lambda_{r}^{*}}{L_{m}}
$$

The d-axis and q-axis reference currents components in combination with the estimated rotor flux angle using SMO are utilized to generate the reference three-phase stator currents $i_{a b c}^{*}$. Two voltage and two current transducers are utilized to sense the two-phase stator voltages and two-phase stator currents signals. The third phase voltage and current is evaluated based on the three-phase balance concept. The actual threephase motor currents-based transducers signals are compared with the reference three-phase motor currents and the deviations between these signals are fed into the hysteresis band current controller (HBCC). The outputs of the HBCC are the input gate pules of the three-phase inverter using IGBT switches. The drive system is driven with speed command signal obtained from permanent magnet synchronous motor (PMSM). The reference speed is the output of V/F speed-controlled inverter and the IM rotor speed is scaled up/down based on the gearbox turns ratio. The wheel speed for EV drive applications is the output speed from the gear box device.

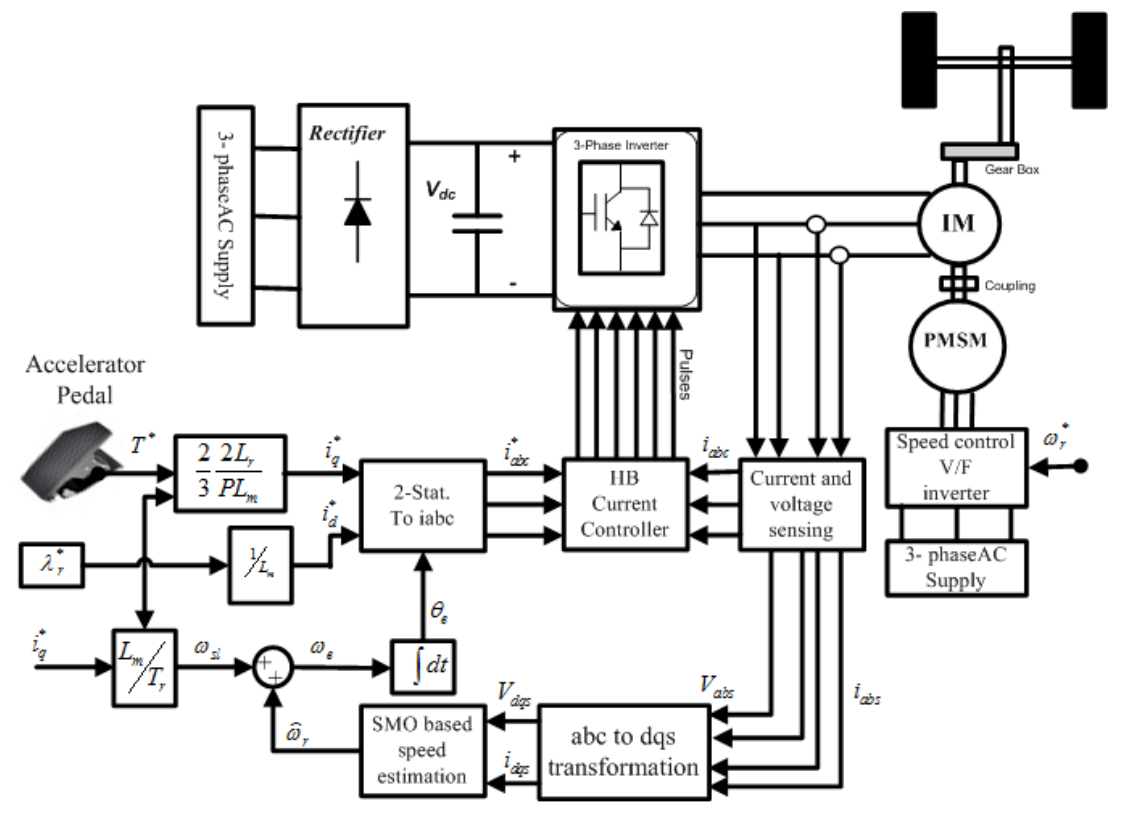

Figure 1. Schematic diagram of the SMO for IRFOC of the encoderless IM based torque control drive

\section{LABORATORY SYSTEM SETUP}

The schematic diagram of the proposed encoderless IM drive using SMO speed estimator utilizing TDC based on IRFOC strategy of EV applications has been implemented in the laboratory using DSpaceDS1 103 control board for $5.5 \mathrm{~kW}$ IM as shown in Figure 2. The machine under test was operated concerning encoderless torque-controlled drive conditions. The drive speed is imposed by the speed-controlled load dynamometer PMSM. The specifications of the IM that are used in all laboratory tests are given in Table 1. The IM is fed from a 3-phase VS-inverter, which has six isolated gate bipolar transistors (IGBT's) switches and its pulses are obtained by utilizing a gate driver board. The DS1103 control board is mounted in a

Smart integration of drive system for induction motor applications in electric ... (Mohamed K. Metwaly) 
personal computer (PC). This Digital Signal Processing (DSP) board has a set of on-board peripherals such as digital-to-analog (D/A), analog-to-digital (A/D) converters and position encoder interfaces. It also provides the necessary digital input/output (I/O) ports, timer function I/O capture, and PWM gate pulses generation ports. Over PC, all calculations are done and performed using the Matlab/Simulink environment. The Simulink control models are compiled using a Texas Instruments Matlab/Simulink real-time interface environment and downloaded to the DSpace-DS1103 board utilizing DSpace software tools.

Table 1. The rated values and specifications of the IM

\begin{tabular}{ll}
\hline Specitication & Value \\
\hline Rated output power & $5.5 \mathrm{~kW}$ \\
Rated voltage & $186 \mathrm{~V}$ \\
$\mathrm{~F}$ & $50 \mathrm{~Hz}$ \\
$\mathrm{P}$ & 2 \\
$\mathrm{R}_{\mathrm{s}}$ & $0.294 \Omega$ \\
$\mathrm{R}_{\mathrm{r}}$ & $0.14325 \Omega$ \\
$\mathrm{L}_{\mathrm{s}}$ & $57.3 \mathrm{mH}$ \\
$\mathrm{L}_{\mathrm{r}}$ & $57.3 \mathrm{mH}$ \\
$\mathrm{L}_{\mathrm{m}}$ & $56.43 \mathrm{mH}$ \\
$\mathrm{J}$ & $0.12 \mathrm{~kg} \cdot \mathrm{m}^{2}$ \\
$\mathrm{~B}$ & $0.018 \mathrm{~N} \cdot \mathrm{m} . \mathrm{s} / \mathrm{rad}$ \\
\hline
\end{tabular}

For the experimental execution, a real-time Simulink control model is done and then compiled to the DSP board utilizing software tools. The accelerator pedal is utilized for inserting the reference torque in EV application by the driver, the reference currents $i_{q}^{*}$ and $i_{d}^{*}$ are utilized to generate the reference phase currents $i_{a}^{*}, i_{b}^{*}$ and $i_{c}^{*}$ using the inverse Park's transformation formula. The motor voltages and currents are sensed using LA25-NP Hall-effect current sensors and LV25-P Hall-effect voltage sensors, respectively. The motor measurements are sent back to the DSP control board via the A/D ports. The differences between the sensed phase currents and their corresponding reference phase current are fed as an input to hystereses bands to generate pulses for the three-phase inverter. The generated pulses trigger the IGBT gates of the inverter to feed the IM with suitable voltages and frequency. The optical encoder with 1024-pulse resolution is utilized to sense the rotor speed/position, this sensed signal is utilized as a reference signal for comparison purposes with the estimated speed signal. The IM is coupled to a speed-controlled load dynamometer (PMSM).

To verify and prove the efficiency of the proposed TCD and encoderless speed estimation based on the SMO observer with EV applications, the laboratory waveforms are taken at various operating conditions. These conditions include the IM drive at very low and zero speeds in motoring and regenerating modes and with sudden load variations. Also, the running at zero electrical frequency is also evaluated. The results are taken under IRFOC of the encoderless IM drive. The IM was running under TCD condition with standard $d q$ current loops, and the estimated flux angle is used for vector transformation of the rotor-oriented $d q$ - frame. The drive system was connected to a speed controlled PMSM whose speed is monitored.

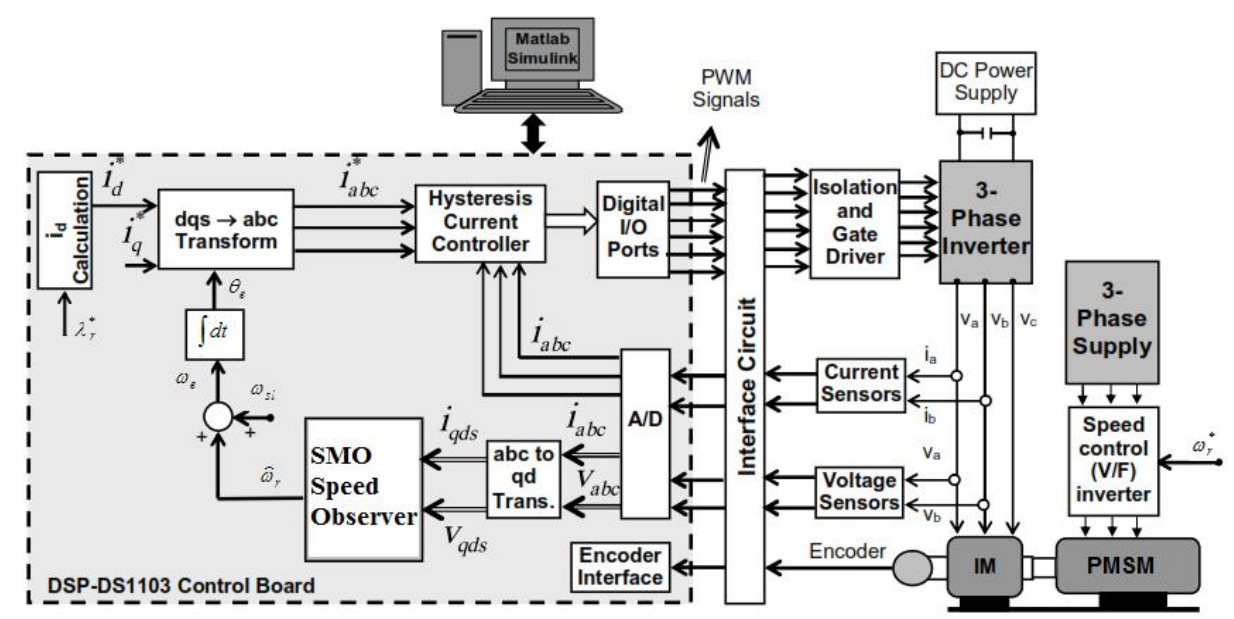

Figure 2. Schematic diagram of the laboratory setup for SMO-based speed estimation of IRFOC encoderless IM drive using DSpace-DS1103 control board 


\section{RESULTS AND DISCUSSIONS}

\subsection{Very low and zero speed operation}

The starting performance of the encoderless IM with TCD using the SMO for speed estimation at very low speed of $20 \mathrm{rpm}$ under rated load condition is shown in Figure 3. In Figure 3.a the upper graph presents the rotor speed reference obtained from the position encoder (black) and the estimated speed using the SMO (gary-dotted), while the error between these two signals is depicted in the middle graph in rpm. It is noted that the difference between these two speeds is approximately $13 \mathrm{rpm}$ during starting which dies out after $0.5 \mathrm{sec}$. This proves the accuracy of estimated speed signal and the effectiveness of the SMO. This can be smartly achieved without any encoder. The load current $\left(i_{q}\right)$ is depicted in the lower graph. The stator currents in $\alpha \beta$ frames are shown in the upper graph of Figure 3(b). In order, to present the advantages of the SMO, the rotor flux angles and the difference between the reference (black) and estimated flux (gray-dotted) angles are depicted in the middle and lower graphs in Figure 3(b). The figure presents the rotor flux angle smartly obtained from the encoderless control method using the SMO technique (gray-dotted) and the flux angle from the sensor-based (reference) current model (black). It is noted that the estimated flux angle tracks the reference one smartly and smoothly with small flux angle deviation as shown in the lower graph of Figure 3 (b). The application of SMO provides better matching to the real values of the rotor flux angle without any encoder.

Figure. 4 shows the laboratory waveforms during the dynamic speed responses of the encoderless IM drive using the SMO technique at rated load and speed change. The IM drive system was operated at speed reference $20 \mathrm{rpm}$ under rated load condition, then a sudden speed change to zero speed was applied at $\mathrm{t}=18 \mathrm{sec}$, then back to $20 \mathrm{rpm}$ at $\mathrm{t}=48 \mathrm{sec}$. The encoderless drive operates in the motoring mode. It is observed that the encoderless drive shows a significant performance with excellent speed estimation accuracy with approximately $8 \mathrm{rpm}$ deviation which dies out soon after transients. Also, the deviation between the reference flux angle and the estimated flux angle (based on the SMO technique) is illustrated in the lower graph of Figure 4(b). As it is observed, the angle deviation stays within a few degrees as depicted in the lower graph of Figure 4(b).

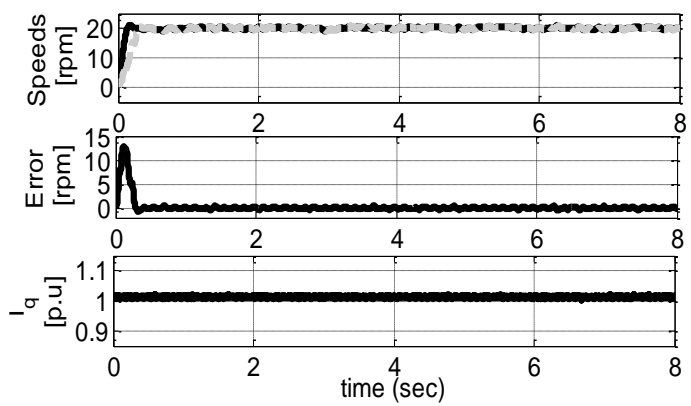

(a)

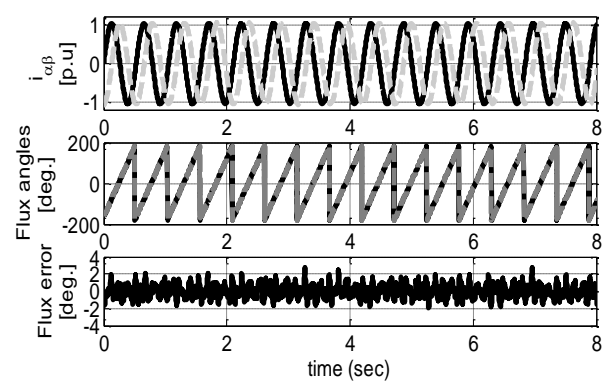

(b)

Figure 3. Laboratory evaluation of fixed low speed at $20 \mathrm{rpm}$ during starting period at the rated load; (a) the subfigures are a comparison of actual (black), estimated (grey-dotted) speeds, speed estimation error (rpm), and load torque current (p.u), (b) the subfigures are $\alpha$ - $\beta$ current, comparison of reference (black) and estimated (grey-dotted) flux angles, and flux angle error

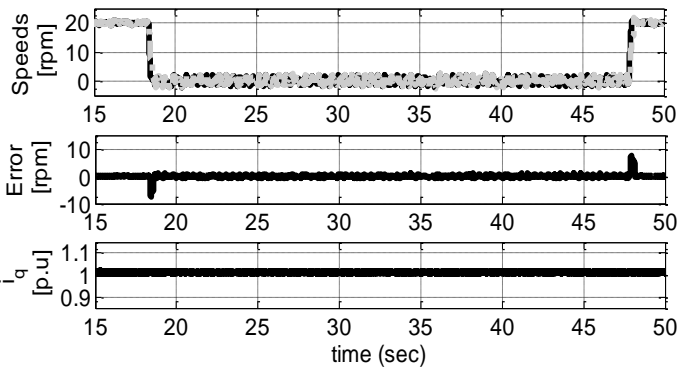

(a)

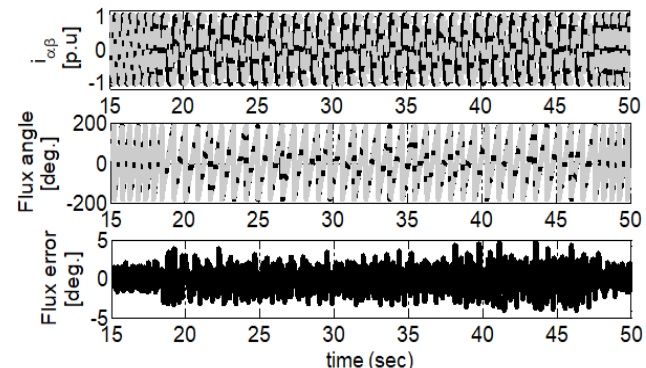

(b)

Figure 4. Laboratory evaluation at step speed changes (20 rpm $\rightarrow 0 \mathrm{rpm} \rightarrow 20 \mathrm{rpm}$ ) at the rated load; (a) speed comparison, error, and load torque current, (b) $\alpha$ - $\beta$ current, flux angle comparison, and error 


\subsection{Sudden load disturbances at very low and zero speeds}

The laboratory waveforms showing the performance of the encoderless IM based TCD using the SMO with sudden applying and removing the rated load torque for $20 \mathrm{rpm}$ speed reference at $t=8 \mathrm{sec}$ and $t=41 \mathrm{sec}$, respectively in the motoring mode are shown in Figure 5. The Laboratory waveforms showing applying and removing the rated-load torque for reference speed zero are also presented as depicted in Figure 6. A rated load torque step is applied at $t=12 \mathrm{sec}$ and removed at $t=32 \mathrm{sec}$. As it is noted, a good matching between the measured and estimated speeds is achieved since the estimated speed follows the measured one and recovers quickly under load impact. The estimated signals can successfully track the measured ones during the transient and steady states. A considerable reduction of the speed estimation error of approximately $20 \mathrm{rpm}$ during transient operation to zero rpm in steady state is observed. It is evident that the SMO works properly, especially in the motoring mode at very low and zero speeds under sudden load disturbances. It can be seen that the speed, the current, the rotor flux angle are correctly observed. The actual rotor flux angle tracks the estimated rotor flux angle of the SMO technique, with only limited error as depicted in the middle and lower graphs of Figure 5(b) and Figure 6(b) respectively. The deviation between the actual rotor flux angle and the estimated flux angle stays within a few degrees. This also indicates that the speed control of encoderless IM based TCD using the SMO works well.

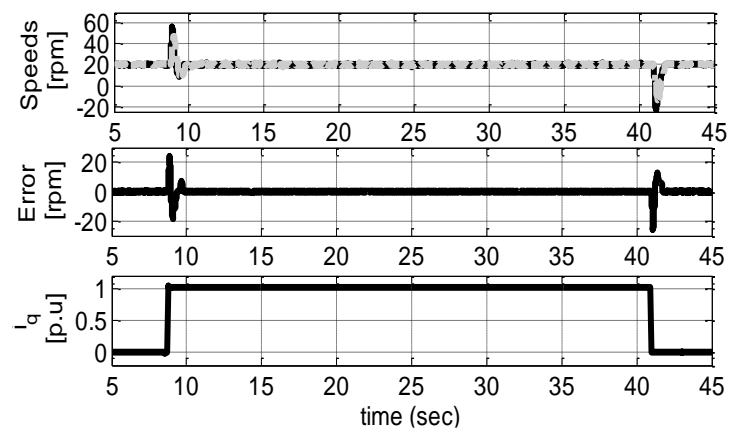

(a)

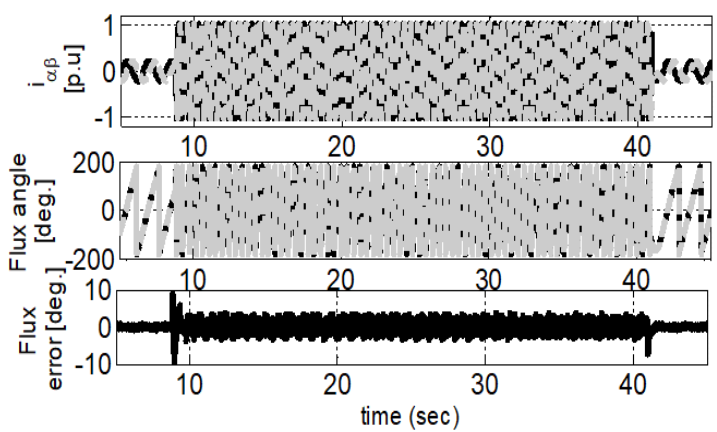

(b)

Figure 5. Laboratory evaluation during sudden application and removal of the rated load torque at speed of $20 \mathrm{rpm}$; (a) speed comparison, error, and load torque current, (b) $\alpha$ - $\beta$ current, flux angle comparison, and error
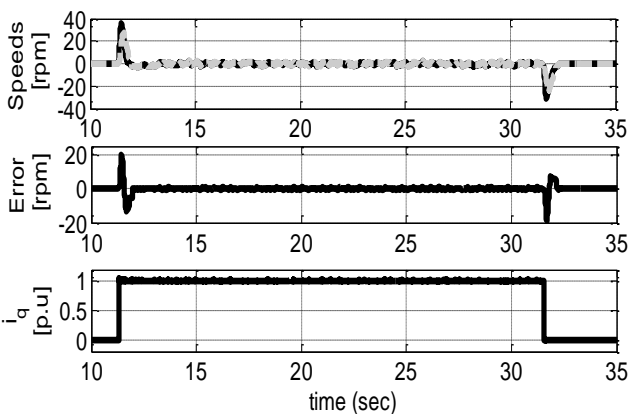

(a)



(b)

Figure 6. Laboratory evaluation during sudden application and removal of the rated load torque at zero speed;

(a) speed comparison, error, and load torque current, (b) $\alpha$ - $\beta$ current, flux angle comparison, and error

\subsection{Speed reversal at very low speed}

The laboratory waveforms illustrate the performance of the encoderless IM based TCD using the SMO during very low speed reversals are shown in Figure 7. The IM is operated at rated load condition. The reference speed is suddenly changed from $-20 \mathrm{rpm}$ to $20 \mathrm{rpm}$ at $\mathrm{t}=7 \mathrm{sec}$, then back to $-20 \mathrm{rpm}$ at $\mathrm{t}=21 \mathrm{sec}$, and changed to $20 \mathrm{rpm}$ at $\mathrm{t}=34 \mathrm{sec}$. The encoderless drive operates first in the regenerating mode $(\mathrm{t}=0 \rightarrow 7$ $\mathrm{sec})$, then in the motoring mode $(\mathrm{t}=7 \rightarrow 21 \mathrm{sec})$, again in the regenerating mode $(\mathrm{t}=21 \rightarrow 34 \mathrm{sec})$, and finally in the motoring mode $(\mathrm{t}=34 \rightarrow 40 \mathrm{sec})$ as illustrated in Figure 7 . It has been observed that the encoderless 
IM based TCD using the SMO show a significant performance with excellent estimation accuracy during very low speed reversals in the motoring and regenerating modes of operation. Also, the estimated rotor flux angle tracks the reference one with small error as shown in the middle and lower graphs of Figure 7(b).
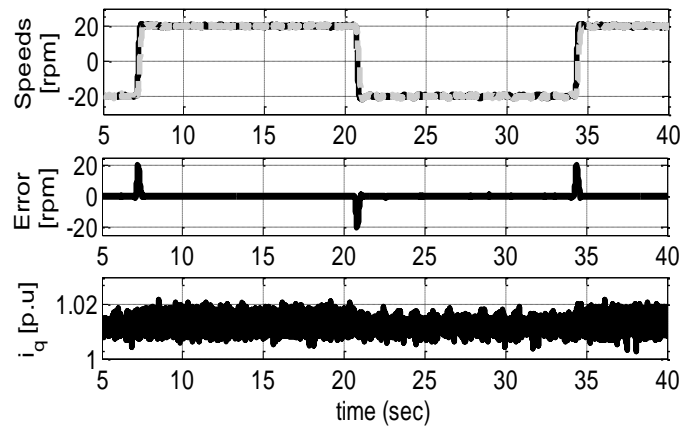

(a)



(b)

Figure 7. Laboratory evaluation at very low speed reversal $\pm 20 \mathrm{rpm}$ at rated load; (a) speed comparison, error, and load torque current, (b) $\alpha$ - $\beta$ current, flux angle comparison, and error

\section{CONCLUSION}

In this paper, a smart integration of drive system based on encoderless IM, TCD, and indirect rotor field-oriented control IRFOC using the SMO is utilized for speed estimation in EV applications. The SMO is utilized to estimate the rotor speed from stator currents/voltages measurements. The mathematical model of SMO is presented, and laboratory implemented. The TCD is used as accelerating torque which generates the reference torque current in EV by the driver. In the absence of encoder sensor, TCD based on IRFOC requires encoderless speed estimator for flux angle determination. Laboratory waveforms confirm the effectiveness of the proposed encoderless IM based TCD using the SMO at very low and zero speeds. The rotor speed/flux angle estimation accuracy is noted under load torque/speed variations.

\section{ACKNOWLEDGEMENTS}

This work was supported in part by Scientific Research Deanship, Taif University under Research Group 6147-440-1.

\section{REFERENCES}

[1] A. Borisevich, and G Schullerus, "Energy Efficient Control of an Induction Machine Under Torque Step Changes," IEEE Transactions on Energy Conversion, vol. 31, no. 4, pp. 1295-1303, 2016.

[2] M. Pacas, "Sensorless drives in industrial applications," IEEE Industrial Electronics Magazine, vol. 5, no. 2, pp. $16-23,2011$

[3] S. Xepapas, A. Kaletsanos, F. Xepapas and S. Manias, "Sliding-mode observer for speed-sensorless induction motor drives," IEE Proceedings-Control Theory and Applications, vol. 150, no. 6, pp. 611-617, 2003.

[4] M. S. Zaky, M. M. Khater, S. S. Shokralla, and H. A. Yasin, "Wide-Speed-Range Estimation with Online Parameter Identification Schemes of Sensorless Induction Motor Drives," IEEE Transactions on Industrial Electronics, vol. 56, no. 5, pp. 1699-1707, 2009.

[5] Y. Fan, L. Zhang, M. Cheng, and K. T. Chau," Sensorless SVPWM-FADTC of a New Flux-Modulated PermanentMagnet Wheel Motor Based on a Wide-Speed Sliding Mode Observer," IEEE Transactions on Industrial Electronics, vol. 62, no. 5, pp. 3143-3151, 2015.

[6] F. Chen and M. W. Dunnigan, "Comparative study of a sliding-mode observer and Kalman filters for full state estimation in an induction machine," IEE Proceedings-Electric Power Applications, vol. 149, no. 1, pp. 53-64, 2002.

[7] Z. Qiao, T. Shi, Y. Wang, Y. Yan, C. Xia, and X. He, "New Sliding-Mode Observer for Position Sensorless Control of Permanent-Magnet Synchronous Motor," IEEE Transactions on Industrial Electronics, vol. 60, no. 2, pp. 710-719, 2013.

[8] Y. Zhao, W. Qiao, and L. Wu, "Improved Rotor Position and Speed Estimators for Sensorless Control of Interior Permanent-Magnet Synchronous Machines," IEEE Journal of Emerging and Selected Topics in Power Electronics, vol. 2, no. 3, pp. 627-639, 2014.

[9] H. Kim, J. Son, and J. Lee, "A High-Speed Sliding-Mode Observer for the Sensorless Speed Control of a PMSM," IEEE Transactions on Industrial Electronics, vol. 58, no. 9, pp. 4069-4077, 2011 
[10] G. Foo, and M. F. Rahman, "Sensorless Sliding-Mode MTPA Control of an IPM Synchronous Motor Drive Using a Sliding-Mode Observer and HF Signal Injection," IEEE Transactions on Industrial Electronics, vol. 57, no. 4, pp. 1270-1278, 2010.

[11] L. Zhao, J. Huang, H. Liu, B. Li and W. Kong, "Second-Order Sliding Mode Observer with Online Parameter Identification for Sensorless Induction Motor Drives," IEEE Transactions on Industrial Electronics, vol. 61, no. 10, pp. 5280-5289, 2014.

[12] C. Lascu and G. D. Andreescu, sppSliding-Mode Observer and Improved Integrator With DC-Offset Compensation for Flux Estimation in Sensorless-Controlled Induction Motors," IEEE Transactions on Industrial Electronics, vol. 53, no. 3, pp. 785-794, 2006.

[13] Y. Zhao, W. Qiao, and L. Wu, "An Adaptive Quasi Sliding-Mode Rotor Position Observer-Based Sensorless Control for Interior Permanent Magnet Synchronous Machines," IEEE Transactions on Industrial Electronics, vol. 28, no. 12, pp. 5618-5629, 2013.

[14] H. Lee and J. Lee, "Design of Iterative Sliding Mode Observer for Sensorless PMSM Control," IEEE Transactions on Control Systems Technology, vol. 21, no. 4, pp. 1394-1399, 2013.

[15] G. Wang, Z. Li, G. Zhang, Y. Yu, and D. Xu, "Quadrature PLL-Based High-Order Sliding-Mode Observer for IPMSM Sensorless Control with Online MTPA Control Strategy," IEEE Transactions on Energy Conversion, vol. 28, no. 1, pp. 214-224, 2013.

[16] G. Foo, and M. F. Rahman, "Direct Torque Control of an IPM-Synchronous Motor Drive at Very Low Speed Using a Sliding-Mode Stator Flux Observer," IEEE Transactions on Power Electronics, vol. 25, no. 4, pp. 933-942, 2010.

[17] R. Morales-Caporal, E. B. Huerta, C. Hernandez, M. A. Arjona, and M. Pacas, "Transducerless Acquisition of the Rotor Position for Predictive Torque Controlled PM Synchronous Machines Based on a DSP-FPGA Digital System," IEEE Transactions on Industrial Informatics, vol. 9, no. 2, pp. 799-807, 2013.

[18] X. Zhang, L. Sun, K. Zhao, and L. Sun, "Nonlinear Speed Control for PMSM System Using Sliding-Mode Control and Disturbance Compensation Techniques," IEEE Transactions on Power Electronics, vol. 28, no. 3, pp. 1358-1365, 2013.

[19] Y. Feng, J. Zheng, X. Yu, and N. V. Truong, "Hybrid Terminal Sliding-Mode Observer Design Method for a Permanent-Magnet Synchronous Motor Control System," IEEE Transactions on Industrial Electronics, vol. 56, no. 9, pp. 3424-3431, 2009.

[20] L. Yuan, F Xiao, J Shen, M Chen, Q. Shi, L. Q. feng, "Sensorless control of high-power interior permanent magnet synchronous motor drives at very low speed," IET Electric Power Applications, vol. 7, no. 3, pp. 199-206, 2013.

[21] M. Comanescu, "Single and double compound manifold sliding mode observers for flux and speed estimation of the induction motor drive," IET Electric Power Applications, vol. 8, no 1, pp. 29-38, 2014.

[22] E. Azad, S. Gadoue, D. Atkinson, H. Slater, P. Barrass, and F. Blaabjerg, "Sensorless Control of IM Based on Stator-Voltage MRAS for Limp-Home EV Applications," IEEE Transactions on Power Electronics, vol. 33, no. 3, pp 1911-1921, 2018.

[23] M. K. Metwally, "Control of Four Switch Three Phase Inverter Fed Induction Motor Drives Based Speed and Stator Resistance Estimation," International Journal of Power Electronics and Drive Systems (IJPEDS), vol. 4, no. 2, pp. 192-203, 2014

[24] M. K. Metwally, "Direct Torque Control of Four Switch Three Phase Inverter fed Induction Motor Sensorless Speed Drive," International Journal of Power Electronics and Drive Systems (IJPEDS), vol. 5, no. 2, pp. 153-165, 2014.

[25] O. Barambones and P. Alkorta, "Position Control of the Induction Motor Using an Adaptive Sliding-Mode Controller and Observers," IEEE Transactions on Industrial Electronics, vol. 61, no. 12, pp. 6556-6565, 2014.

[26] M. S. Zaky, M. K. Metwaly, Said A. Deraz, and H. Z. Azazi, "A New Adaptive SMO for Speed Estimation of Sensorless Induction Motor Drives at Zero and Very Low Frequencies," IEEE Transactions on Industrial Electronics, vol. 65, no. 9, pp. 6901-6911, 2018. 